\title{
El Mundial 78 en la prensa política argentina: entre la "fiesta", el nacionalismo y los derechos humanos ${ }^{1}$
}

\section{Marcelo Borrelli² Laura Oszust ${ }^{3}$}

Recibido: 2016-05-26

Enviado a pares: 2016-05-31
Aprobado por pares: 2016-06-28

Aceptado: 2016-06-28

DOI: 10.5294/pacla.2018.21.1.2

Para citar este artículo / to reference this article / para citar este artigo Borrelli, M. y Oszust, L. (2018). El Mundial 78 en la prensa política argentina: entre la "fiesta", el nacionalismo y los derechos humanos. Palabra Clave, 21(1), 11-35. DOI: 10.5294/pacla.2018.21.1.2

\section{Resumen}

En este artículo se analiza el posicionamiento editorial de las revistas políticas argentinas Somos, Extra y Redacción frente al Mundial de fútbol jugado en Argentina en junio de 1978 durante la última dictadura militar (19761983). El desarrollo del evento fue un momento propicio para que el Gobierno militar intentara mostrar una imagen positiva del país frente a las acusaciones internacionales que indicaban su responsabilidad en la violación a los derechos humanos. En ese marco, la prensa política local legitimó la versión del Gobierno y rechazó las denuncias internacionales que recaían sobre el país. Por otra parte, las revistas analizadas ofrecieron su punto de vista sobre los efectos que la organización del Mundial tendría en la política

\footnotetext{
1 La elaboración de este artículo ha sido facilitado por el proyecto PICT 2012-0284 de la Agencia Nacional de Promoción Científica y Tecnológica (Argentina), dirigido por Marcelo Borrelli, que tiene como objetivo el estudio de diversas revistas políticas publicadas durante el periodo 1976-1983.

2 orcid.org/0000-0001-7091-4885. Consejo Nacional de Investigaciones Científicas y Técnicas, Argentina. mborrelli@conicet.gov.ar

3 orcid.org/0000-0003-4904-5587. Universidad de Buenos Aires, Argentina.
} 
interna, estimulados por los festejos populares que acompañaron el éxito del seleccionado argentino en el certamen. En este ámbito, mostraron similitudes y diferencias en torno a cómo el Gobierno debía utilizar el capital político que dejaba el Mundial, de qué manera debían estrecharse las relaciones entre militares y civiles y qué rol tendría que cumplir el presidente militar Jorge Videla en esa pretendida convergencia de intereses.

\section{Palabras clave}

Prensa local; argentina; derechos humanos; dictadura; periodismo (Fuente: Tesauro de la Unesco). 


\section{The 1978 World Cup in Argentina's Political Press. Between "Party," Nationalism, and Human Rights}

\section{Abstract}

In this paper we analyze the editorial position of Argentina's political magazines Somos, Extra, and Redacción regarding the FIFA World Cup that took place in June 1978 in Argentina during the last military dictatorship (19761983). The event was the auspicious moment for the military government to attempt to show a positive image of the country in the face of international accusations about its responsibility in the violation of human rights. In this context, the local political press legitimized the government's version and rejected the international claims against the country. Furthermore, the analyzed magazines offered their points of view on the effects that organizing the World Cup had on domestic politics, stimulated by the popular celebrations that followed the success of Argentina's national team in the competition. They showed similarities and differences as to how the Government should use the political capital left by the World Cup, how the relationship between the military and civilians should be strengthened, and what would be the role of military president Jorge Videla in the alleged convergence of interests.

\section{Keywords}

Local press; Argentina; human rights; dictatorship; journalism (Source: Unesco Thesaurus). 


\section{A Copa do Mundo de 78 na imprensa política argentina. Entre a "festa", 0 nacionalismo e os direitos humanos}

\section{Resumo}

Neste artigo analisa-se o posicionamento editorial das revistas políticas argentinas Somos, Extra e Redacción no que se refere à Copa do Mundo de futebol realizada na Argentina em junho de 1978 durante a última ditadura militar (1976-1983). O desenvolvimento do evento foi um momento propício para que o Governo militar tentasse mostrar uma imagem positiva do país diante das acusações internacionais que indicavam a sua responsabilidade na violação dos direitos humanos. Nesse entorno, a imprensa política local legitimou a versão do Governo e rejeitou as denúncias internacionais que recaiam sobre o país. Por outra parte, as revistas analisadas ofereceram seu ponto de vista sobre os efeitos que a organização do Mundial teria na política interna, estimulados pelos festejos populares que acompanharam o sucesso da seleção argentina no certame. Neste âmbito, mostraram similitudes e diferenças com relação à maneira como o Governo devia utilizar o capital político deixado pela Copa do Mundo, de que maneira deviam estreitar-se as relações entre militares e civis e qual papel deveria ser cumprido pelo presidente militar Jorge Videla nessa pretendida convergência de interesses.

\section{Palavras-chave}

Imprensa local; argentina; direitos humanos; ditadura; jornalismo (Fonte: Tesauro da Unesco). 


\section{Introducción}

Este artículo tiene como objetivo analizar la posición editorial de las revistas políticas argentinas Extra, Redacción y Somos ante el Mundial de Fútbol de 1978, jugado durante la última dictadura militar autodenominada Proceso de Reorganización Nacional (1976-1983). El Mundial 78 tuvo gran repercusión en la prensa política tanto por lo que implicaba para el país su realización como por su exposición ante la mirada internacional por las violaciones a los derechos humanos de las que era acusado el Gobierno militar argentino. Frente a ello, el Gobierno utilizó el acontecimiento futbolístico para mostrar una imagen positiva, mientras que los medios de comunicación tuvieron un rol clave en el ámbito interno como difusores y legitimadores de esa representación.

El estudio resulta valioso si se tiene en cuenta que no hay investigaciones especializadas sobre estas revistas frente a la coyuntura propuesta y por el rol que la prensa de carácter político tuvo durante los años dictatoriales. Debido a que el control estatal se centró en especial en los medios escritos de mayor alcance e influencia en la opinión pública, la prensa de carácter político, más restringida en su circulación, aunque dirigida hacia un público informado y en algunos casos con poder para influir sobre la actualidad política, pudo dar cuenta de temas, problemas y análisis vinculados a la realidad nacional excluidos o tratados superficialmente por la prensa diaria.

\section{Marco metodológico y teórico del estudio}

El corpus elegido para analizar y confrontar la posición editorial de las revistas está compuesto por los editoriales, las crónicas sobre el evento mundialista y las notas de opinión de los principales analistas. Entendemos la sección editorial como la voz institucional del medio, dado que constituye el espacio en el que se resume el posicionamiento de la publicación y se sistematiza explícitamente su línea política e ideológica (Borrat, 1989). En la cobertura periodística, seguimos a Peralta (2009), quien la define como una

constelación de notas de diversos géneros discursivos, referidas a un mismo suceso, la distribución de esas notas en el papel [...], los paratextos que orientan la lectura [...] y la distribución en cada texto, de los distintos aspectos tematizados en relación con ese suceso, la 
cesión del espacio enunciativo a diferentes "voces", el contenido de esas voces y cuestiones tales como la selección de las palabras, las modalizaciones, etc. (p. 15)

Los objetivos concretos del estudio fueron analizar las valoraciones, las representaciones y los significados otorgados por las revistas a tres temas primordiales: 1) los efectos del Mundial sobre la "imagen" internacional del país en relación con los derechos humanos, 2) la repercusión política del Mundial para la dictadura y 3 ) los efectos políticos de las manifestaciones ciudadanas de alegría por las victorias deportivas de la selección argentina.

Para sostener esta metodología cualitativa de investigación, hemos trabajado desde lo que Demaziére y Dubal (1997, citado por Kornblit, 2004) denominan modo analítico para el uso de los datos, que se propone analizar las construcciones que los actores - en este caso los medios- realizan de los temas a partir de la identificación de las principales categorías que organizan su relato. De manera que nos interesa comprender cómo y por qué las revistas se posicionaron de una determinada manera frente al evento y a sus efectos políticos.

Desde el punto de vista teórico, entendemos las publicaciones periódicas como actores políticos, comprendiendo el actor político como "todo actor colectivo o individual capaz de afectar el proceso de toma de decisiones en el sistema político" (Borrat, 1989, p. 10), cuyo ámbito distintivo es el de la influencia sobre otros actores políticos. ${ }^{4}$ Por tanto, al dar cuenta de su discurso editorial, esbozaremos una interpretación sobre cuál fue la directriz de esa influencia por parte de las revistas y, en la comparación, si se pueden establecer matices, diferencias y continuidades.

\section{Las revistas}

Redacción nació en marzo de 1973 bajo la dirección del periodista Hugo Gambini, quien en ese entonces ya tenía una importante trayectoria en medios escritos. Su publicación era mensual, su extensión promediaba las 68

4 Si bien Borrat utiliza la categoría para describir la acción de los periódicos independientes, planteamos que puede ser extensiva a este tipo de revistas, que tienen como objetivo distintivo, justamente, "lo político". 
páginas y su tirada en el periodo osciló entre los 15000 y 30000 ejemplares. ${ }^{5}$ A fines de la década de 1990, Redacción pasó a llamarse Redacción Económi$c a$ y fue publicada hasta 2003. La revista no estaba separada por secciones, pero abarcaba diversos temas, desde la actualidad política, pasando por la economía, la cultura y la historia, entre otros. Se presentaba como un exponente del periodismo de interpretación, destinada a un lector informado.

Desde una concepción muy crítica con el peronismo, Redacción apoyó el golpe de Estado de 1976 y reconoció la legitimidad de las Fuerzas Armadas para modelar el nuevo sistema político, pero con cierta premura les reclamó a los militares que concretaran algún tipo de propuesta hacia los dirigentes políticos y convergieran hacia una democracia "madura" en un plazo no excesivo. Hacia 1978, al no existir una propuesta política precisa por parte del Gobierno militar, y frente a su escaso interés en incorporar a los partidos políticos, la revista parecía albergar una mayor desconfianza en torno a los verdaderos objetivos de las Fuerzas Armadas en el poder (Borrelli, 2014).

El primer número de Somos salió a la venta el 24 de septiembre de 1976 y se publicó por última vez el 22 de diciembre de 1993. Su director era Aníbal C. Vigil, quien también se desempeñaba como presidente de la Editorial Atlántida, empresa de medios de la cual formaba parte la revista. Su periodicidad durante la etapa de estudio fue semanal, y se publicó los días viernes. En 1978, tuvo una circulación neta pagada que promedió los 33000 ejemplares. ${ }^{6}$ Se trataba de una publicación orientada a fracciones de la clase media, que incluía sectores empresariales, interesados en la coyuntura política y económica nacional, así como en la vida cultural y en temáticas internacionales. También Somos se distinguió por publicar notas de interés más general o "color".

Desde el inicio de la dictadura, la Editorial Atlántida ofreció un apoyo explícito y militante al Gobierno de las Fuerzas Armadas, que se concretó

\footnotetext{
5 El dato fue proporcionado por Hugo Gambini (consulta por correo electrónico el 26 de abril de 2013 y entrevista realizada por Borrelli a Gambini el 5 de febrero de 2014).

6 Según el Instituto Verificador de Circulaciones.
} 
desde varias de sus publicaciones, como sus revistas insignias Gente y la Actualidad y Para Ti. Este apoyo tuvo como uno de sus emblemas el rechazo a las denuncias que eran difundidas desde el extranjero sobre las violaciones a los derechos humanos que ocurrían en la Argentina, además de sostener un anticomunismo militante, coincidir en la visión autoritaria que la dictadura profesaba en ámbitos como el educativo y el de la organización familiar o difundir notas estigmatizadoras sobre los "guerrilleros" y "subversivos". Somos, además, se destacará por su adhesión al liberalismo económico y su apoyo a la política económica de José Martínez de Hoz, ministro de Economía de la dictadura en el periodo 19761981 (Borrelli y Gago, 2014).

Extra fue una revista de aparición mensual dirigida por el periodista Bernardo Neustadt, que se publicó entre julio de 1965 y mayo de 1989. Formaba parte del entramado multimediático del que Neustadt era propietario y en el cual ejercía como periodista — que incluía para la década de 1970 diversos medios gráficos, programas radiales y televisivos - y nació con el objetivo de abordar temas relacionados con la política, la economía y el plano internacional. Era una publicación destinada al poder político y económico de la Argentina, que también buscaba hacerse eco en un ciudadano informado y con una orientación tendiente al liberalismo económico. Su extensión promediaba las 50 páginas. Siguiendo el estilo de su director, en algunas de sus notas se utilizaba un lenguaje coloquial y tenía una diagramación flexible. Aunque no contamos con datos de su tirada, ${ }^{7}$ a partir de ciertas fuentes como Fernández Díaz (1993), podemos señalar que $E x$ tra no fue un éxito editorial y que su permanencia en el mercado se debió más a los anuncios con los que contaba y a la fama de su director en otros medios que a un gran número de lectores.

Extra apoyó explícitamente el golpe militar (González, 2010) y aprobó la idea de una restauración del "orden público" y el disciplinamiento social que plantearon las Fuerzas Armadas. Desde el inicio expresó abiertamente su aprobación a dos de los pilares de la dictadura: la "lucha antisubversiva" y la política económica de Martínez de Hoz, y se

7 Extra no era auditada por el Instituto Verificador de Circulaciones. 
ubicó así dentro de la "zona de confianza" de la dictadura (Iturralde y Borrelli, 2014). Paradójicamente, esta cercanía con el actor militar también le permitió hacer saber sus reparos con los "excesos represivos" y su apoyo a los sectores del propio Gobierno que consideraba más "moderados" o proclives a tender lazos con los dirigentes civiles, lo cual le valió a la publicación sufrir algunas represalias al quedar envuelta en las pujas internas de las Fuerzas Armadas.

\section{El contexto político del Mundial 78}

El 6 julio de 1966, durante la presidencia de facto del general Juan Carlos Onganía, Argentina había obtenido la sede del XI Campeonato Mundial de Fútbol. Junto con los vaivenes de la política nacional, su organización estuvo en duda hasta poco tiempo antes de su realización. Para alejar la incertidumbre que generó el golpe de Estado de 1976, la dictadura se vio en la obligación de ratificar su organización y en julio de 1976 lo hicieron a través de la Ley 21349, que declaró al Mundial como un evento de "interés nacional” y que creó el Ente Autárquico Mundial '78 (EAM 78), que sería el responsable de la organización (Gilbert y Vitagliano, 1998; Llonto, 2005; Oliva y Tutino, 2004).

Hacia mediados de 1978 la dictadura gozaba de cierto capital político frente a la opinión pública, donde prevalecían tendencias favorables para una apertura pactada y controlada por las Fuerzas Armadas, estimuladas por cierta recuperación económica durante 1977 y el "orden restablecido" luego de la etapa más dura de la "lucha antisubversiva", represión clandestina que ya se había cobrado una gran proporción de sus víctimas y empezaría a desacelerarse desde mediados de 1978 (Novaro y Palermo, 2003, pp. 119 y 235). A instancias de esta efectividad represiva, la "victoria sobre la subversión", como una de las principales bases de legitimidad de los militares en el poder, estaba perdiendo su fortaleza porque no se avanzaba con claridad en la propuesta de una institucionalización futura para el país, lo cual aletargaba el paso hacia otra etapa del Gobierno militar. Por eso, el Mundial significaba para el Gobierno un "gesto de fuerte positividad” (Schindel, 2012, p. 284), que intentaría dejar atrás el pasado represivo para inaugurar una nueva etapa. 
Asimismo, durante 1978 las autoridades militares habían retomado con particular ahínco la denuncia sobre la existencia de una "campaña antiargentina" atizada desde el exterior por el "terrorismo subversivo" que estaba difundiendo una "imagen falsa" del país. Acontecimientos de índole internacional, como la organización del Mundial, el Congreso Mundial del Cáncer que se desarrolló en octubre de ese año, la presión que venía ejerciendo los Estados Unidos y la Organización de Estados Americanos en foros internacionales por la violación de los derechos humanos, sumado a la de los exiliados y otras organizaciones humanitarias internacionales, ${ }^{8}$ dejaron a la dictadura altamente expuesta a la consideración internacional y la obligaron a desplegar una estrategia que contrarrestara la imagen negativa del país. Así fue que el Gobierno respondió montando una "contracampaña” de denuncia que utilizó argumentos nacionalistas — muy efectivos para la idiosincrasia político/cultural nacional - y versiones conspirativas que atizaron el temor al acecho de la "amenaza subversiva externa" contra la nación. Según Franco (2002), la estrategia del régimen apeló a mecanismos cómplices para generar consensos en el frente interno y contó con el aval de la prensa, que en términos generales apoyó y sobredimensionó la teoría de la "amenaza" de la injerencia externa. El "discurso denuncialista" (Franco, 2002) de la dictadura tuvo su punto álgido en especial a partir de abril de 1978, con el pico de exaltación nacionalista durante el Mundial, jugado en el país del 1 al 25 de junio. Durante esos días se desplegó un poderoso "nosotros inclusivo", que asoció la acción del Gobierno con la deportiva, la de la nación y la de todo un pueblo, que disolvió diferencias y conflictos en una supuesta identidad nacional renacida (Alabarces, 2002 y 2008; Schindel, 2012). Y, en un país donde el fútbol tiene un gran peso social y simbólico para la identidad nacional, "ganar equivalía a confirmar la autoimagen futbolística nacional, mientras que perder sería una humillación” (Novaro y Palermo, 2003, p. 162).

8 La organización del Mundial y del Congreso Mundial del Cáncer fueron ocasiones propicias para que los exiliados se organizaran para denunciar lo que ocurría en el país, que formó el Comité de Boicot al Mundial de Fútbol en Argentina y un "contra” Congreso de Cáncer en Francia, los cuales repercutieron ampliamente en la opinión pública europea (Franco, 2008; Llonto, 2005; Verbitsky, 2009; Yankelevich y Jensen, 2007). 


\section{Las revistas y el Mundial 78}

Las tres revistas coincidieron en otorgarle al Mundial 78 una fuerte impronta política en sus evaluaciones, tanto en lo atinente a la relación entre el Gobierno militar con la sociedad civil como en las expresiones que el evento despertó en la propia población.

En el caso de Extra, una característica pronunciada de la revista fue la de interpretar El Mundial como un evento clave para mejorar la imagen externa del país. Para su director con el Mundial se iban a terminar con "las dudas que querían ensuciar nuestro modo de vivir" (Neustadt, 1978a, p. 17) y, en el mismo sentido, el analista Andrés Bronté (1978) indicaba: "Aún no ganando en la cancha, Argentina ganó en el mundo. No tiene precio: ninguna agencia de publicidad extranjera $[\ldots]$ hubiese podido mostrar mejor nuestra imagen que la realidad que vivimos" (p. 26). Este tipo de expresiones eran posibles, porque la represión impulsada por el Gobierno se había realizado de forma clandestina y uno de sus pilares fue el ocultamiento - para el cual la autocensura de la prensa tendrá un rol fundamental-, pese a los rumores y las informaciones que parcialmente recorrían el tejido social. Y que la mirada sospechosa viniera de actores internacionales activaba la reacción de tipo nacionalista que rechazaba esos juicios como tendenciosos o falaces.

Junto con este efecto externo positivo, para Extra la organización del Mundial también tenía réditos internos, en cuanto era una muestra del carácter nacional, aún contra los propios prejuicios del pueblo argentino, e indicaba un camino. En este campo, el director resaltaba que se había derrotado el "escepticismo" y que la inversión económica que había supuesto era "barata" si con ella se enterraba para siempre la "sensación de constante fracaso". El señalamiento de un problema casi ontológico del ciudadano argentino en torno al "escepticismo" también era resaltado en aquellos días por el secretario de Cultura de la Nación, Raúl Casal, quien declaraba que ese era el principal defecto argentino y por tanto debían "desaparecer los escépticos para que nazca la esperanza” (citado por Gilbert y Vitagliano, 1998, p. 100). Un recurso común de la dictadura y sus apoyos civiles: el de acusar al ciudadano común por los problemas estructurales del 
país. Por último, para el director, la organización había revelado la "capacidad del país para producir lo que le indican bien claro”, por tanto, valía la pena pensar - en otra comparación con la política - en un mundial "institucional", no por solo un mes, sino para "toda la vida" (Neustadt, 1978b, p. 17). Es decir, implícitamente, Neustadt daba cuenta de que el Gobierno aún carecía de un programa claro y a largo plazo para la reorganización institucional del país, lo cual en efecto se irá convirtiendo en uno de sus principales problemas políticos.

Una vez finalizado el evento y concretada la obtención de la Copa del Mundo por el seleccionado argentino, en su edición de julio de 1978,9 Extra revalidó en forma contundente desde su tapa su apoyo a la "contracampaña” del Gobierno militar. Allí tituló, con fondo patrio celeste y blanco: "REALIDAD ARGENTINA: 6 - LA CALUMNIA: 0". ${ }^{10}$ Neustadt apelaba en su editorial a la analogía entre el fútbol y la política para resaltar el gran impacto que había tenido el Mundial (Neustadt, 1978, p. 20). Allí utilizaba el estilo apologético ${ }^{11}$ para asegurar que se había ganado el "Campeonato Mundial contra la Calumnia", porque un país "difamado" había exhibido su "calidad de vida”, el "Campeonato Mundial de la Organización”, el "Campeonato Mundial del Comportamiento", porque "en las calles la fiesta no tuvo una sola mancha, un desaliño, y la cortesía y la educación resultaron los distintivos apasionantes de la sociedad argentina” y el "Campeonato Mundial de la Seguridad", ya que "en la difamada República Argentina, frente a 6200 periodistas extranjeros [... ], ni una vitrina rota”. Téngase en cuenta que el discurso autoritario y disciplinador que se amplió durante la dictadura hacía un fuerte hincapié en la concepción "higiénica" del orden público y en la buena conducta de la población, por ejemplo, antes del Mundial se había realizado una campaña en los medios destinada a ese fin (Gilbert y Vitagliano, 1998), de ahí la valoración positiva que hacía el director sobre el comportamiento de la ciudadanía. Por

9 La agenda temática de este número se "mundializó", ya que tanto su editorial como una gran mayoría de las notas y entrevistas versaban en torno al evento.

10 En alusión al triunfo de Argentina frente a Perú por 6 a 0, que le daría la clasificación al equipo argentino a la final del Mundial (el partido frente a Perú prontamente quedó envuelto en sospechas por su abultado resultado).

11 En cuanto busca difundir los beneficios de determinado sistema de gobierno y suele tener un tono propagandístico (Rivadeneira Prada, 1986, citado por Castelli, 1991). 
otra parte, se detenía en la relación entre el poder militar y la sociedad, que apuntaba a que el país “aplaudió a la Junta Militar" — sin que esta hubiera buscado el aplauso, subrayaba - y hasta la "fiesta" vivida había cambiado el "estilo" del habitualmente parco presidente militar Jorge Videla. En efecto, el día después de la obtención de la Copa Mundial Videla había salido a saludar en el balcón de la casa de Gobierno a un grupo de jóvenes que festejaban en la Plaza de Mayo, en el centro de Buenos Aires, a quienes luego bajó a saludar personalmente (Clarín, 1978, pp. 2-3). Según el director, la efusividad mundialista lo había obligado a "salir a la calle y a un balcón, que no quiso" [cursivas en el original $].{ }^{12}$

Téngase en cuenta que desde el inicio de la dictadura Videla fue revestido de una imagen de austeridad republicana, un "republicanismo antipolítico”, según Novaro y Palermo (2003, p. 55), que fue recurrentemente celebrada por la gran prensa nacional y contó con la aprobación de las clases medias y altas. Incluso durante los primeros años de la dictadura existió una verdadera "videlatría" (Jordán, 1993) por parte de amplios sectores de la sociedad civil, en tanto que las palabras del presidente eran valoradas positivamente y su figura recibía muestras de aceptación en la vía pública.

En definitiva, para Extra, el Mundial 78 logró aventar las sospechas que recaían sobre la Argentina en torno a su "imagen” y se planteó como una base de despegue de algunos de los problemas políticos que persistían tanto en términos "institucionales", ya que la dictadura no había esbozado con claridad cuál sería el futuro político del país, como en la relación Gobierno-sociedad civil, puesto que parecía ser una oportunidad para mejorar ese vínculo. En este campo, Extra será un activo precursor para que los militares en el poder no se aislaran y se acercaran a los dirigentes civiles propensos al acuerdo (Borrelli e Iturralde, 2016).

En la edición de junio de la revista Redacción, su director Gambini expresaba un rotundo aval a la organización del evento en su editorial "El éxito

12 El uso del balcón de la casa de gobierno había sido una característica distintiva del tres veces presidente electo de la Argentina Juan Domingo Perón en su relación con el pueblo, y su legado "populista” era el que justamente la dictadura quería desterrar. De ahí también el hincapié en el “cambio de estilo” de Videla. 
del Mundial". Allí recordaba que hasta los más "pesimistas" y los "detractores" del campeonato estaban "orgullosos de sentirse argentinos" frente a la "organización elogiable" y el "despliegue espectacular" del certamen. Pero diferenciaba la loable actitud que había demostrado la "gente que trabaja" - con su "trato afable, su humildad y su excelente disposición" — a la de "los oportunistas", que se habían "encandilado" con el "negocio del Mundial" y habían subido los precios en forma exorbitante con lo cual ahuyentaron al turismo. Como bien señala Alabarces (2008, p. 19), quien se aprovechaba de la situación para generar ganancias pecuniarias aparecía como un "otro" excluido del potente "nosotros inclusivo" — alegre y solidario—, aunque su sola mención ponía en contradicción la construcción positiva sobre el colectivo de "los argentinos" y mostraba sus fisuras. Pese a estas cuestiones menores, para Gambini, la Argentina había demostrado estar bien preparada y el Mundial había sido la oportunidad para que los periodistas "descubrieran el verdadero país, no el que les gustaba inventarse” (junio de 1978, p. 13).

Al igual que en el caso de Extra, observamos que la repercusión positiva del Mundial sobre la "imagen" internacional del país estuvo en el centro de la escena de las interpretaciones de los analistas y permiten dar cuenta, al menos parcialmente, de hasta qué punto la campaña iniciada por el Gobierno militar había logrado un fecundo consenso en la prensa, que se retroalimentaba con la buena disposición que hallaron los militares en la ciudadanía para "jugar de argentinos" y enrolarse tras las banderas nacionalistas (Novaro y Palermo, 2003, pp. 161-162).

Por su parte, Jorge Koremblit —uno de los columnistas permanentes de la revista - en la misma edición de junio se mostraba mucho más cauto y escéptico que Gambini. En su nota "Después del Mundial", exhibía su desconfianza hacia el "fervor mundialista" que vivía el país y señalaba que, cuando se acallara el "júbilo de la fiesta deportiva, los grandes problemas de la vida nacional volverán a asomar su torvo rostro" (Koremblit, 1978, p. 18). El Mundial había servido para reflejar lo que eran capaces de hacer los argentinos, pero había que volver a la "realidad": "Porque una cosa es construir estadios $[\ldots]$ y otra $[\ldots]$ contribuir $[\ldots]$ a poner en marcha la economía del país", concluía. 
La visión de Koremblit ubicaba el Mundial en una perspectiva diferente de las hasta aquí analizadas, casi como un espectáculo distractivo de los "verdaderos" problemas nacionales. Y más que ser una base de despegue para resolverlos — como se intuía en Extra, por ejemplo- era un paréntesis que los invisibilizaría efímeramente. En esta visión, lo emocional - vinculado al fervor, la pasión y lo festivo- y el corto plazo parecía imponerse sobre la racionalidad y el largo plazo. Un discurso deudor de aquellas lecturas que observan al fútbol, en cuanto espectáculo, como un acontecimiento de evasión para las masas.

En el editorial del número de julio, Gambini eligió hacer hincapié en los festejos populares. Bajo el título "La euforia popular" remarcaba que esta había "desbordado" toda previsión y había hecho olvidar momentáneamente las diferencias de todo tipo (sociales, ideológicas, políticas, etc.). Destacando la noción de homogeneidad y consenso, aseguraba que "durante el mundial todos fuimos iguales e igualmente patriotas" $y$, como lo hacía Neustadt, resaltaba que se había festejado "sin romper nada". Asimismo, apuntaba que el "espontáneo" festejo había sido "sano", "razonable" y "maduro", ya que "se gritaba en nombre del país porque se lo sentía de verdad, sin pudor alguno, para que se supiera que lo queremos a pesar de todas las dificultades y frente a todas las agresiones externas". En efecto, los festejos por el Mundial fueron asociados por gran parte de la prensa a los de un "sano carnaval" (Schindel, 2012, pp. 292-296), en cuanto se permitía la suspensión de la rutina y de ciertas convenciones sociales, pero sin el contenido transgresor que tradicionalmente incluía lo carnavalesco (Bajtin, 2003).En la lectura de Schindel (2012, p. 297), indicaban un país que había estado "enfermo" y ahora se "purificaba" para renacer. Buscando una explicación a tanta euforia popular, además del apasionamiento nacional por el fútbol, el director encontraba un ingrediente "estimulante" en la "campaña en contra del país", que, reconocía, "nos hipersensibilizó". Pese al optimismo, Gambini finalizaba con una llamada admonitoria ${ }^{13}$ hacia las autoridades militares: destacaba sí que el "aplauso sincero" del pueblo hacia el Gobierno era

13 En cuanto exhorta al cumplimiento de reglas, advierte peligros, llama al orden y a la concordia en busca de un equilibrio permanente en el sistema frente a las contradicciones que alcanzan niveles de grave enfrentamiento (Rivadeneira Prada, 1986, citado por Castelli, 1991). 
importante porque otorgaba "un aval de confianza mutua entre gobernados y gobernantes", pero indicaba que había que "calibrarlo cuidadosamente" y "caminar hacia una Democracia plena, sin engaños ni retaceos" (Gambini, 1978 , p. 13). De manera que, en un tono enfático, alertaba sobre las tendencias endógenas de las Fuerzas Armadas y resaltaba la necesidad de ir tendiendo puentes con los civiles, en un discurso que Redacción profundizará en este tiempo (Borrelli, 2014).

Somos ubicó en tapa al Mundial en su edición del 9 de junio con el titular la "La locura del Mundial", donde resaltaba cómo el evento había cambiado "la vida de los argentinos". Esto se vivenciaba en la alteración del ritmo de vida familiar, en los asuetos en la Administración pública, en las grandes inversiones de los medios en la cobertura del evento o en las mujeres que se adherían al "fenómeno", un tema particularmente resaltado a través de entrevistas a mujeres o fotografías femeninas en los estadios ( $\mathrm{Ri}$ tacco, 1978, pp. 8-16).

El secretario de Redacción de Somos, Gustavo Landívar, era contundente sobre los efectos políticos positivos que el Mundial tenía para las Fuerzas Armadas, destacado desde el propio título de su editorial: "Los réditos políticos del Mundial". ${ }^{14}$ Ellos se observaban en los aplausos que había recibido la Junta en la inauguración del torneo, en la "interrupción aprobatoria" del discurso presidencial o en que la manifestación espontánea que se había formado para celebrar el triunfo de la selección argentina en su debut ante Hungría había tenido como denominador común el grito de “¡viva Argentina!", una alegría que además iba "más allá de un mero triunfo deportivo”. Landívar lo comparaba con la manifestación que había celebrado el triunfo peronista en las elecciones presidenciales del 11 de marzo de 1973, donde, en contraposición, la característica de los cánticos era "el odio". ${ }^{15}$ Era claro

14 De forma contradictoria con esta interpretación, desde la sección "Así nos ve Europa" del 23 de junio, destinada, como veremos, a publicar notas de medios extranjeros sobre el Mundial, Somos se quejaba que los corresponsales extranjeros basaban sus crónicas en cuestiones políticas y no deportivas (Somos, 23 de junio de 1978, p. 58).

15 Ese día la fórmula presidencial del Frente Justicialista de Liberación encabezada por Héctor Cámpora y Vicente Solano Lima ganó las elecciones, lo cual significó el retorno al poder del peronismo luego de dieciocho años de proscripción electoral nacional. 
que para el editorialista se trataba de dos argentinas diferentes: la del populismo y su prédica confrontativa frente a la del orden y la alegría. De la misma manera que Gambini y Neustadt, subrayaba la organización "digna y eficiente" que había demostrado que los argentinos "podemos hacer las cosas bien”. Pero también, en la misma línea que Koremblit en Redacción, mostraba su temor a que los "éxitos parciales alimenten exitismos peligrosos, típicos de épocas pasadas". La clave era que la euforia deportiva se manifestara en otras "actitudes y circunstancias más importantes", referidas a la transformación definitiva del país (Landívar, 1978, p. 17).

Como lo dejaba entrever, la visión internacional sobre la Argentina fue un eje clave de la cobertura de Somos, que se expresó particularmente a través de la sección "Así nos ve Europa". Allí durante el evento publicó una selección de notas sobre el país aparecidas en medios extranjeros, con la intención de resaltar los aspectos positivos de las coberturas o directamente criticando aquellas de contenidos negativos. ${ }^{17}$ El propio Landívar, en su editorial del 23 de junio de 1978, se quejaba de las acusaciones de las revistas francesas contra el Gobierno argentino por atentar contra la libertad o no respetar los derechos humanos (Landívar, 1978, p. 13). E intentaba deslegitimarlas al informar que Paris Match y L'Express, "campeonas de los derechos humanos”, y en cuyas páginas se publicaban reportajes a "cabecillas del terrorismo argentino", como Rodolfo Galimberti o Mario Firmenich, ${ }^{18}$ se habían negado a publicar una solicitada de empresarios argentinos que describía la agresión que había sufrido el país en manos de la "subversión". El hecho de que solo le abrieran la puerta a "los subversivos", y no a quienes los combatían, destacaba la forma "tendenciosa" con la que se manejaban en torno a las noticias referidas al país.

16 Desde sus números iniciales, Somos se distinguió por publicar crónicas que denunciaban el accionar de la "subversión” en el exterior, que en su parecer explicaba la imagen negativa del país. En abril de 1978, por ejemplo, exaltaba desde su tapa "Complot contra la Argentina", la campaña europea de denuncia sobre las "supuestas" violaciones a los derechos humanos en el país (Borrelli y Gago, 2014).

17 Vale resaltar que de todas maneras a través de esta sección el lector de Somos pudo tener acceso a opiniones negativas sobre el país y su Gobierno, allende que la intención de la revista era criticarlas y deslegitimarlas.

18 Líderes de Montoneros, la organización política armada del peronismo de izquierda, que tuvo su apogeo durante la primera parte de la década de 1970. 
La cobertura de la edición del 16 de junio estuvo enfocada en las cuestiones deportivas y de la organización mundialista, como en las vivencias de la ciudadanía en cada sede del evento (Ritacco, 1978, pp. 14-17). El siguiente número del 23 de junio, a través de la nota "El país de fiesta", resaltó los festejos luego del triunfo frente a Perú por 6 a 0 , que le diera a la Argentina la clasificación a la final del Mundial ante Holanda (Ritacco, 1978, pp. 8-11). En ambas ediciones, el Mundial no fue el tópico central de la tapa.

Luego de la obtención de la copa Mundial, Somos trasladó el tema a su tapa nuevamente el 30 de junio con un recordado titular: "Un país que cambió". Allí aparecía en primera plana la poco habitual imagen de un Videla en una actitud de cierto desenfado emocional, sonriente y alzando los brazos, en pleno festejo. Al igual que Neustadt, la revista mostraba el contraste en el estilo presidencial para hablar de un "cambio" en general para el país. Somos ofrecía así una contundente lectura política sobre lo ocurrido en el Mundial. La idea de un "cambio" en el día a día que se expresaba en la edición del 9 de junio retornaba ahora, pero respecto de un cambio más profundo que debía darse a largo plazo. Se condensaban en la crónica algunas de las opiniones ya analizadas, que confirmaban la idea del "cambio" en varios ámbitos del quehacer nacional, que mostraban un pueblo virtuoso y unido:

Todo fue civilizado [...] Se gritó solamente Argentina, y no otra palabra, nombre o consigna partidista. No hubo personalismos: hubo fervor nacional [...] Se festejó con sana alegría, sin depredaciones, sin violencia. Todos celebraron las conquistas: ricos, pobres [...] funcionarios, obreros, empresarios.

Los taxistas se habían mostrado gentiles con los turistas - devolviendo hasta dinero perdido-, los futbolistas no habían apelado al juego brusco, el director técnico, César Menotti, había impuesto una forma de juego "coherente", no había adoptado "posiciones demagógicas" (al no incluir a jugadores demandados por los hinchas) y el proceso había durado cuatro años sin ser interrumpido por el "exitismo" habitual de otro tiempo. Finalmente, un "hecho clave" que registraba este cambio y mostraba la "significación” de esos días era la concentración espontánea en la Plaza de Mayo 
que había pedido por Videla. ${ }^{19}$ Para Somos, que el fútbol hubiera sido "factor de unificación" era un explicación superficial, en realidad era un "detonante", porque "había algo más" en el entusiasmo patrio de los festejos. Se trataba de la "compleja urdimbre" que había vivido el país desde 1969 al ir creciendo el "terrorismo subversivo", años de "luchas desangrantes entre argentinos", que forjaron una concepción "derrotista del país" para hacer cosas en conjunto, frustraciones además agravadas por la experiencia peronista de 1973-1976. Sin embargo, en los últimos días, la revista observaba ese "cambio de mentalidad", ${ }^{20}$ que tenía su más claro registro en las adhesiones que había tenido Videla en los estadios, cuya política era "antidemagógica”, a diferencia, claro, de lo que ocurría con los liderazgos pretéritos. Pero con esta nueva realidad no bastaba. La cuestión era saber "qué hacer para que esta transformación que produjo el Mundial de Fútbol no se pierda, no se diluya". En principio, los gobernantes no debían dejar que el "capital político" — que para algunos suponía un plebiscito, señalaba- no quedase en un mero recuerdo. Y la ciudadanía debía preservar esa "unidad en torno a la patria", luego de haber salido de una "guerra sucia" por culpa de la "subversión". La nota finalizaba con una sutil advertencia al Gobierno militar: el país había demostrado su "capacidad de hacer", ahora un "liderazgo eficaz" debía trasladar esa fuerza a todas las actividades del país. Como señalaba: "La Argentina quiso y pudo hacer un Mundial de Fútbol. Deberá ahora querer y poder ganar el segundo Mundial, el de su futuro como país. El pueblo parece estar preparado. Falta que los líderes acepten el reto" (Somos, 30 de junio de 1978). De manera que, desde un medio afín al Gobierno militar, se le indicaba que aún carecía de una orientación política clara y definida, como también de un líder político que la plasmara.

\section{Conclusiones}

En relación con la cobertura periodística del Mundial, las tres publicaciones le otorgaron un lugar relevante, aunque Somos, por ser una publicación de interés más general y la única de edición semanal, es la que más espacio

19 La fotografía más grande que acompañaba la nota era justamente la de Videla desde el balcón de la casa de Gobierno ante una nutrida concurrencia (Somos, 30 de junio de 1978, p. 9).

20 Latiguillo al que apelaba el ministro Martínez de Hoz para explicar el cambio que demandaba su política, como mencionamos, abiertamente apoyada por Somos. 
le otorgó, tratando, además, diversos aspectos del tema, desde lo deportivo hasta lo sociopolítico. También se distinguió por la inclusión de gran cantidad de fotografías, de vital importancia en el contexto mundialista en cuanto "matriz simbólico-dramática" y un poderoso dispositivo "de interpelación y constitución de lo popular” (Sunkel, 1985).

Las tres publicaciones coincidieron en darle un sentido político fuerte y amplio al Mundial. En primera medida, interpretaron que el evento había contradicho las versiones de la "campaña antiargentina", aunque fueron Somos y Extra las más apologéticas para con la versión del Gobierno militar y que más recursos estilísticos y periodísticos pusieron en juego sobre este punto. Todas resaltaron que la organización había demostrado lo que los argentinos podían hacer y que significaba una realidad promisoria para el futuro. La "unidad nacional" fue ponderada en forma homogénea, contrastada, además, por Somos para valorar los cambios producidos hacia 1978 con los tiempos de la división y el faccionalismo de los años peronistas. Por su parte, los analistas de Somos y Redacción advirtieron sobre los límites del "éxito" y recalcaron que los elementos auspiciosos que había puesto de relieve el Mundial no resolvían los problemas de fondo del país; en todo caso, la energía observada por esos días debía canalizarse hacia los fines más relevantes de la grandeza nacional.

Respecto del Gobierno militar, coincidieron en destacar positivamente los aplausos a la Junta Militar brindados por los espectadores en los estadios de fútbol. Sin embargo, también indicaron que tanto este hecho como los festejos en general no debían ser interpretados como un apoyo cerrado y total hacia la Junta, ya que indicaron la necesidad de ir dando pasos concretos para resolver los problemas nacionales. Redacción señaló con claridad que debía encaminarse el país "hacia una Democracia plena"; Somos, si bien dentro de un discurso apologético hacia las Fuerzas Armadas, remarcó que había que generar un "liderazgo eficaz" para canalizar políticamente la vitalidad ciudadana que había expresado el Mundial, y Extra fue enfático en relación con la necesidad de "abrir" el juego político a las nuevas generaciones, sin que esto supusiera elecciones a corto plazo (Neustadt, 1978a). Extra y Somos hicieron hincapié en el carácter no de- 
magógico del liderazgo de Videla y en cómo el Mundial había modificado su estilo parco hacia otro más expresivo. Ambos destacaron la convocatoria de jóvenes en la Plaza de Mayo, que finalizó con el dictador saludando desde el balcón, una reminiscencia del pasado peronista, que, sin embargo, interpretaron en la nueva clave de la autoridad no demagógica que imponía una relación distinta entre gobernantes y gobernados. Redacción no se sumó a esta mirada y no se manifestó al respecto. Por su parte, Somos es la que interpretó de manera más contundente que el Mundial había implicado un "cambio" profundo en los diversos planos del quehacer nacional, aunque reconocía que la nueva actitud que había surgido durante el torneo debía vigorizarse en el futuro para consolidar así a la nación.

La aparición de multitudes espontáneas en el espacio público, luego de dos años y tres meses de férreo disciplinamiento social desde el Estado, obligó a la consideración de las revistas, que en forma mancomunada ponderaron positivamente que los festejos populares se habían desarrollado de forma ordenada y pacífica. Al destacar que no se hubiesen cometido hechos de violencia, dieron cuenta de la sensibilidad que ocasionaba que la "violencia" se visibilizara en el espacio público, dentro de una sociedad civil sacudida por hechos de este tipo. También festejaron la idea de una "unidad nacional" policlasista y polisectorial, lo cual parecía contrastar implícitamente con un pasado de conflictos. En efecto, fue Somos la más explícita en este aspecto, al mencionar que las multitudes hacían rememorar al país peronista, pero, a diferencia de aquellos años, la revista mostraba su satisfacción con la novedad de estas masas disciplinadas, patriotas, sin divisiones y que expresaban una "sana alegría”.

Como actores políticos, puede concluirse que las tres revistas impusieron una doble impronta a su editorialización: una, la de influir sobre sus audiencias para realizar una valoración positiva sobre lo relativo al evento, en cuanto celebraron su organización y el modo en que se expresaron los festejos populares, defendieron al Gobierno militar en torno a la cuestión de la imagen y los derechos humanos y coincidieron en resaltar el reconocimiento ciudadano ante el éxito organizativo; otra, la de influir sobre el actor político militar al indicar lo que consideraban cuestiones pendientes 
para el Gobierno, que iban desde la necesidad de abrir el juego político a las jóvenes generaciones (Extra), encaminar con mayor rapidez el "Proceso" hacia la democracia (Redacción) o buscar liderazgos "fuertes" (Somos) para canalizar la energía del Mundial hacia objetivos de transformación más importantes.

\section{Referencias}

Alabarces, P. (2002). Fútbol y patria. Buenos Aires: Prometeo.

Alabarces, P. (2008). La justa deportiva sin igual: avatares del Mundial 78. Oficios Terrestres, 22, 16-22.

Bajtin, M. (2003). La cultura popular en la Edad Media y en el Renacimiento. Madrid: Alianza Editorial.

Borrat, H. (1989). El periódico, actor político. Barcelona: Gustavo Gili.

Borrelli, M. (2014). ¿Hacia la “democracia prometida?” La revista Redacción y la cuestión política durante los años de Videla (1976-1981). Pilquen. Sección Ciencias Sociales, 1(17), 1-15.

Borrelli, M. y Gago, M. P. (2014). "Prepararse para un nuevo ciclo histórico": la revista Somos durante los primeros años de la dictadura militar (1976-1978). Rihumso, 2(5), 17-40.

Borrelli, M. e Iturralde, M. (6-9 septiembre 2016). La revista Extra y la "convergencia cívico-militar" durante los primeros años de la dictadura (1976-1978). Ponencia presentada en XVIII Congreso de REDCOM: Comunicación, derechos y la cuestión del poder en América Latina. Ciudad Autónoma de Buenos Aires, La Plata.

Bronté, A. (junio 1978). El mundial... (campeones o no). En Extra, p. 26.

Castelli, E. (1991). Manual de periodismo. Buenos Aires: Plus Ultra. 
Clarín (27 junio 1978). La Plaza de Mayo fue epicentro del festejo. En Clarín Mundial, pp. 2-3.

Extra (julio 1978). Mundial, p. 6.

Fernández Díaz, J. (1993). Bernardo Neustadt: el hombre que se inventó a sí mismo. Negocios, odios y amores del periodista más poderoso de la Argentina. Buenos Aires: Sudamericana.

Franco, M. (2002). La “campaña antiargentina”: la prensa, el discurso militar y la construcción de consenso. En J. Casali de Babot y M. Victoria Grillo (eds.), Derecha, fascismo y antifascismo en Europa y Argentina (pp. 195-225). San Miguel de Tucumán: Universidad de Tucumán.

Franco, M. (2008). El exilio: argentinos en Francia durante la dictadura. Buenos Aires: Siglo XXI.

Gambini, H. (junio de 1978). El éxito del mundial. En Redacción, p. 13.

Gambini, H. (julio de 1978). La euforia popular. En Redacción, p. 13.

Gilbert, A. y Vitagliano, M. (1998). El terror y la gloria: la vida, el fútbol y la política en la Argentina del Mundial 78. Buenos Aires: Norma.

González, M. (2010). De la "Argentina impotente" a la "democracia eficiente”. Extra frente al golpe de Estado de 1976. Ponencia presentada en XIV Jornadas Nacionales de Investigadores en Comunicación. Universidad Nacional de Quilmes, Quilmes.

Iturralde, M. y Borrelli, M. (2014). Desde la "zona de confianza” de la dictadura: la revista Extra y la "lucha antisubversiva" (1976-1978). Intersecciones en Comunicación, 8, 119-136.

Jordán, A. R. (1993). El proceso 1976-1983. Buenos Aires: Emecé. 
Koremblit, J. (junio de 1978). Después del mundial. En Redacción, p. 18.

Kornblit, A. (coord.) (2004). Metodologías cualitativas en ciencias sociales. Buenos Aires: Biblos.

Landívar, G. (9 de junio de 1978). Los réditos políticos del Mundial. Somos, p. 17.

Landívar, G. (23 de junio de 1978). ¿Quiénes no respetan los derechos humanos? En Somos, p. 13.

Llonto, P. (2005). La vergüenza de todos (el dedo en la llaga del Mundial 78). Buenos Aires: Ediciones Madres de Plaza de Mayo.

Neustadt, B. (junio de 1978a). Las divisiones inferiores. En Extra, p. 6.

Neustadt, B. (junio de 1978b). Los jóvenes de 30 años... En Extra, pp. 16-17.

Neustadt, B. (julio de 1978). Cómo vivir sin el Mundial. En Extra, pp. 20-21.

Novaro, M. y Palermo, V. (2003). La Dictadura Militar 1976/1983. Buenos Aires: Paidós.

Oliva, M. y Tutino, S. (2004). La voz institucional del Mundial 78 (Los editoriales del diario Clarín sobre el Mundial de Fútbol Argentina 1978). Ponencia presentada en VI Congreso REDCOM. Facultad de Periodismo y Comunicación Social, UNLP.

Peralta, D. (2009). De ángeles torpes, demonios, criminales: prensa y derechos humanos desde 1984. Buenos Aires: Biblioteca Nacional.

Ritacco, E. (9 junio 1978). La locura del Mundial. En Somos, pp. 8-16.

Ritacco, E. (16 junio 1978). Ahora viene lo mejor. En Somos, pp. 14-17.

Ritacco, E. (23 junio 1978). El país de fiesta. En Somos, pp. 8-11. 
Schindel, E. (2012). La desaparición a diario. Villa María: Eduvim.

Somos (16 junio 1978). Así nos ve Europa, p. 58.

Somos (23 junio 1978). Así nos ve Europa, p. 58.

Somos (30 de junio de 1978). Un país que cambió, pp. 8-16.

Sunkel, G. (1985). Razón y pasión en la prensa popular: un estudio sobre la cultura popular, cultura de masas y cultura politica. Santiago de Chile: ILET.

Verbitsky, H. (13 septiembre 2009). La infiltración. Recuperado de http:// www.pagina12.com.ar/diario/elpais/1-131692-2009-09-13.html

Yankelevich, P. y Jensen, S. (comps.) (2007). Exilios: destinos y experiencias bajo la dictadura militar. Buenos Aires: Libros del Zorzal. 